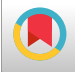

\title{
Systemic Thyroid Hormone Status in Treated Graves’ Disease
}

\author{
Fereidoun Azizi ${ }^{1,{ }^{*}}$, Atieh Amouzegar ${ }^{1}$, Maryam Tohidi $^{2}$, Mehdi Hedayati ${ }^{3}$, Leila Cheraghi ${ }^{1,4}$ and \\ Yadollah Mehrabi ${ }^{5}$ \\ ${ }^{1}$ Endocrine Research Center, Research Institute for Endocrine Sciences, Shahid Beheshti University of Medical Sciences, Tehran, Iran \\ ${ }^{2}$ Prevention of Metabolic Disorders Research Center, Research Institute for Endocrine Sciences, Shahid Beheshti University of Medical Sciences, Tehran, Iran \\ ${ }^{3}$ Cellular and Molecular Endocrine Research Center, Research Institute for Endocrine Sciences, Shahid Beheshti University of Medical Sciences, Tehran, Iran \\ ${ }^{4}$ Department of Epidemiology and Biostatistics, Research Institute for Endocrine Sciences, Shahid Beheshti University of Medical Sciences, Tehran, Iran \\ ${ }^{5}$ Department of Epidemiology and Biostatistics, School of Public Health and Safety, Shahid Beheshti University of Medical Sciences, Tehran, Iran \\ "Corresponding author: Endocrine Research Center, Research Institute for Endocrine Sciences, Shahid Beheshti University of Medical Sciences, Tehran, Iran. Email: \\ azizi@endocrine.ac.ir
}

Received 2019 June 15; Revised 2019 September 07; Accepted 2019 September 29.

\begin{abstract}
Objectives: We aimed to compare the markers of thyroid hormone status in treated euthyroid Graves' patients and levothyroxine (LT4)-treated hypothyroid Graves' patients.

Methods: We collected the data of 277 patients, including 140 radioiodine-treated hypothyroid Graves' patients on LT4 treatment (group 1), 83 euthyroid Graves' patients on methimazole (MMI) therapy (group 2), and 54 euthyroid Graves' patients off MMI or radioiodine therapy for $>2$ years (group 3). After the exclusion of diabetic patients, 130, 73, and 52 patients remained for analysis in groups 1, 2, and 3, respectively. Pearson and Spearman correlation coefficients were employed to assess the relationships between T3:T4 ratio and variables in each group along with univariate and multivariate linear regression models.

Results: The mean age and female/male ratio were similar in the three groups. Serum fT4 was significantly higher and T3, TSH, TPOAb, and TRAb were significantly lower in group 1 than in group 2 and combined groups 2 and 3, which translated to $27 \%$ lower serum T3:T4 ratio in group 1. Higher BMI, serum cholesterol, and LDL cholesterol and lower HDL cholesterol were observed in group 1 than in combined groups 2 and 3. In multivariate regression analysis, the T3:T4 ratio was significantly higher in combined groups 2 and 3 than in group 1 in the presence of BMI and serum fasting blood glucose, triglycerides, and TSH.

Conclusions: Hypothyroid Graves' patients using LT4 exhibited lower T3:T4 ratio despite lower TSH levels and their BMI and lipid parameters differed from those of euthyroid Graves' patients.
\end{abstract}

Keywords: Graves' Disease, Methimazole, Radioiodine, Levothyroxine, Lipid Profile

\section{Background}

The three forms of current therapeutic management of hyperthyroidism have been available for more than 70 years. However, medical treatment by antithyroid drugs is accompanied by a 50\% risk of relapse and ablation of thyroid tissue by radioiodine or surgery may inactivate thyroid at the expense of definitive disease, hypothyroidism (1).

The belief that the restoration of euthyroidism is achieved in all hypothyroid patients by levothyroxine(LT4) monotherapy has come under question in recent years (25 ). The standard management of hypothyroidism by thyroid hormone replacement, mainly LT4 administration, to normalize serum TSH (6) has been based on the knowledge that T4 is converted to T3 by iodothyronine deiodinases in peripheral tissues (7). Assuming that LT4 therapy will maintain an adequate serum pool of T4 and that its con- comitant deiodination in tissues provides physiologic T3 availability has made LT4 monotherapy the ideal replacement treatment for hypothyroidism $(6,8)$.

It has been known that many hypothyroid patients treated with LT4 complain of some symptoms of hypothyroidism (9). An original study by the Morreale de Escobar group showed that euthyroidism cannot be restored in plasma and all tissues of thyroidectomized rats on T4 per se (10). Recent studies have shown that patients on LT4 replacement exhibit significant impairment in psychological well-being (5) and decreased resting energy expenditure when compared to normal controls (4). These abnormal findings occur despite lower serum TSH and substantial risk of having suppressed serum TSH levels in athyreotic patients on LT4 therapy (2). In addition, hypothyroid patients using LT4 showed a lower serum T3:T4 ratio and higher body mass index (BMI) and differed in $12 / 52$ objective and subjective variables compared to 
healthy matched controls (3).

Antithyroid drugs restore euthyroidism in patients with Graves' hyperthyroidism although hyperthyroidism recurs in some patients after the drugs were withdrawn (11). Therefore, many patients experience ablation therapy and exhibit a hypothyroid state after thyroid ablation with radioiodine or surgical treatment or following short- or long-term remission (12).

\section{Objectives}

The current study aimed to evaluate and compare some parameters related to thyroid hormones in treated euthyroid Graves' patients and those on LT4 treatment due to radioiodine-induced hypothyroidism.

\section{Methods}

\subsection{Patients}

A cross-sectional study was conducted on 277 patients, recruited from a single endocrine clinic in Tehran. All eligible patients were approached to ascertain and confirm their consent to participate in this study. Finally, 140 radioiodine-treated Graves' hypothyroid patients on LT4 treatment (group 1), 83 euthyroid Graves' patients on methimazole (MMI) treatment (group 2), and 54 euthyroid Graves' patients who were off MMI or radioiodine therapy for over 2 years (group 3) agreed to participate. The criteria for diagnosis of Graves' disease were signs and symptoms of hyperthyroidism and Graves' orbitopathy and or dermopathy, suppressed TSH $<0.1 \mathrm{mU} / \mathrm{L}$, elevated serum concentration of fT 4 and/or T3, and elevated TRAb or elevated thyroid uptake. The majority of patients were treated with methimazole for 18 months. Radioiodine therapy was performed for those who had a recurrence of hyperthyroidism or because of patient's choice as the initial therapy in $11 \%$ of the patients. There were no variables in patients' selection that could interfere with outcomes.

\subsubsection{Radioiodine-Treated Euthyroid Graves' Patients on LT4} (Group 1)

In this group, 140 patients aged 19 - 70 years were included, who had received radioiodine treatment for diffuse toxic goiter for a median of 44 months before the study and had become hypothyroid 2 - 10 years before recruitment. The results of weight measurement in the medical records of $88 \%$ of the LT4 group patients were available before and after hypothyroidism. All except for three patients had a weight difference of $<1 \mathrm{~kg}$ before LT4 treatment. At the start of LT4 treatment, all patients had TSH of $>10 \mathrm{mU} / \mathrm{L}$ and FT 4 of $10-16 \mathrm{pmol} / \mathrm{L}$. All patients had thyroid function tests and clinic visits every six months. Hypothyroid patients were treated with daily doses of LT4 75-150 $\mu \mathrm{g}$ and attended an endocrine clinic every 6 - 12 months. The dosage of LT4 was adjusted according to serum TSH levels at each visit. In the last two years before the study, serum TSH was out of the normal range in only $11 \%$ of the study sample.

\subsubsection{Euthyroid Graves' Patients on MMI Therapy (Group 2)}

In this group, 83 Graves' patients, aged 19 - 65 years, were on MMI treatment for $23 \pm 12$ months. All were euthyroid in the past 12 months with continuous use of MMI 2.5 - 7.5 mg daily. They attended an endocrine clinic every 4 - 12 months. The dosage of MMI was adjusted at each visit according to serum TSH concentration.

\subsubsection{Euthyroid Graves' Patients on Treatment (Group 3)}

In this group, 54 patients with a history of Graves' disease for a median of 53 months were included, who had been treated with either MMI (32 patients) or radioiodine (22 patients) and had been off thyroid treatment for over two years and were clinically and biochemically euthyroid.

A total of 22 patients had diabetes mellitus and were excluded from the study. After the exclusion of diabetic patients, 130, 73, and 52 patients remained in groups 1, 2, and 3 for analysis, respectively. No subjects had any other acute or chronic diseases or were on corticosteroids and other non-thyroid medications that could alter thyroid hormone levels or weight.

The protocol of the study was approved by the Ethics Committee of the Research Institute for Endocrine Sciences and subjects gave written informed consent before enrollment.

\subsubsection{Clinical Measurements}

Patients were interviewed privately using pretested questionnaires. Initially, information was collected on demographics, smoking status, and family history of diabetes and medication use. To avoid inter-observer error, all measurements were taken by the same person for either gender.

\subsubsection{Anthropometry}

Anthropometric measurements were taken without shoes and wearing light clothing. Height was measured according to the standard protocol. Waist circumference was measured at the level of the umbilicus and hip circumference, over light clothing, at the widest girth of the hip. 


\subsubsection{Laboratory Measurements}

A blood sample was taken after 10 - 12 hours fasting for determination of blood sugar (FBS) and serum concentrations of insulin, lipids, T4, fT4, T3, TSH, TPOAb, and TSH-receptor antibody (TRAb). The standard 2-hours postchallenge plasma glucose test (one-step World Health Organization Procedure) (13) was performed for participants who were not on glucose-lowering agents. Details of measuring plasma glucose and lipids (triglycerides, HDL cholesterol) have been described elsewhere (13).

Serum fT4, T4, and T3 were measured by radioimmunoassay and serum TSH by the immunoradiometric assay using kits (Izotop, Budapest, Hungary). We measured TPOAb by the immunoenzymometric assay (Monobined, Costa Mesa, CA, USA) and TRAb by immunoenzymometric assay (Bio Vendor Laboratory Medicine Inc., Czech Republic). The inter-assay coefficient of variation for all tests was $<8 \%$ and intra-assay coefficient of variation for all tests was $<10 \%$. Reference ranges in euthyroid adults were as follows: fT4, 9-26 pmol/L; T3, 80 -199 ng/dL; TSH, 0.4 - 5.0 mU/L; TPOAb,$<40 \mathrm{IU} / \mathrm{mL}$; and TRAb $<1$ negative, 1 - 1.5 gray zone, and $>1.5 \mathrm{U} / \mathrm{mL}$ positive).

\subsection{Statistical Analysis}

Normal continuous variables were expressed as mean and standard deviation, while median and interquartile ranges were reported for skewed variables. It was found that $82 \%$ of patients were female and only $5 \%$ had a history of smoking; $26 \%$ of 47 male patients and altogether 22 (9\%) of all patients were smokers. Therefore, smoking was not used for the adjustment in the analysis. One-way ANOVA, Bonferroni and Scheffe post hoc, and Mann-Whitney tests were employed for analysis of data. Pearson's and Spearman's correlation coefficients were employed to assess the relationship between the T3:T4 ratio and other normal and skewed variables, respectively. Covariates with p values of less than 0.1 in the univariate analysis were selected to be adjusted in the multivariate model, which was utilized to compare the T3:T4 ratio between the two groups. We set the statistical significance level at a two-tailed type I error of 0.05. All statistical analyses were performed using SPSS version 22.

\section{Results}

Study patients were aged $52.5 \pm 12.9$ years and $18 \%$ were males. The thyroid parameters of the three groups are shown in Table 1 . The mean dose of LT4 was $129 \pm 8 \mu \mathrm{g}$ daily in group 1, corresponding to $1.61 \mu \mathrm{g} / \mathrm{kg}$ body weight, and all patients were clinically euthyroid with normal serum fT4 and T3 concentrations. Serum fT4 concentration was lower and T3:T4 ratio was higher in either of groups 2 and
3 than in group 1 . All other variables were also significantly different between group 2 and group 1 . The differences in serum T3 and TSH concentrations were not statistically significant between groups 1 and 3. In group 3, there was no difference in any variable of systematic thyroid hormone status between those who had a history of MMI and those with radioiodine therapy.

The comparison between group 1 data and combined data of groups 2 and 3 showed significantly higher serum fT4 (15.4 \pm 3.7 vs. $12.8 \pm 3.9 \mu \mathrm{g} / \mathrm{dL}, \mathrm{P}<0.001)$, and significantly lower serum T3 (120 \pm 37 vs. $136 \pm 38 \mathrm{ng} / \mathrm{dL}, \mathrm{P}<$ $0.001)$ and serum TSH (1.36, 0.46 - 3.38 vs. 2.31, 1.37 - 4.06 $\mathrm{mU} / \mathrm{mL}, \mathrm{P}<0.002)$ in group 1 than in combined groups 2 and 3; moreover, the T3: T4 ratio was also $27 \%$ lower in group 1. Serum TSH of $<0.1$ and $<0.4 \mathrm{mU} / \mathrm{L}$ was found in $5 \%$ and $22 \%$ of patients of group 1 and in $2 \%$ and $8 \%$ of patients in groups 2 and 3, respectively; meanwhile, serum TPOAb was higher in groups 2 and 3 than in group 1.

The comparison between group 2 and group 3 showed the significantly higher T3:T4 ratio and TRAb in group 2, but no difference in serum $\mathrm{fT} 4, \mathrm{~T} 3$, and TSH concentrations between the two groups.

Anthropometric data, lipid profiles, and carbohydrate tolerance and resistance are shown in Table 2. The comparison between groups 2 and 3 showed no significant difference in various parameters. Group 2 had lower BMI and serum concentrations of cholesterol, triglycerides, and LDL-cholesterol than group 1. The comparison between group 1 data and combined data of groups 2 and 3 showed that group 1 had significantly higher BMI (28.3 \pm 4.5 vs. 26.7 $\left.\pm 4.3 \mathrm{~kg} / \mathrm{m}^{2}, \mathrm{P}<0.01\right)$, serum cholesterol (203 \pm 3 vs. 191 $\pm 35 \mathrm{mg} / \mathrm{dL}, \mathrm{P}<0.005)$, serum triglycerides (146, 101 - 195 $\mathrm{mg} / \mathrm{dL}$ vs. $118,85-161 \mathrm{mg} / \mathrm{dL}, \mathrm{P}<0.001)$ and serum LDLcholesterol (111 \pm 23 vs. $103 \pm 24 \mathrm{mg} / \mathrm{dL}, \mathrm{P}<0.001)$ and lower HDL-cholesterol (49.4 \pm 12.33 vs. $53.1 \pm 11.6 \mathrm{mg} / \mathrm{dL}, \mathrm{P}$ $<0.02$ ).

\subsection{Associations Between Variables}

Age, BMI, and serum triglycerides, insulin, and HOMAIR in group 1 and serum FBS, TRAb, and TSH in combined groups 2 and 3 were correlated with serum T3:T4 ratio (Table 3).

The results of the univariate regression analysis showed that BMI, FBS, insulin, triglycerides, and TSH had $\mathrm{p}$ values of $<0.1$ (Table 4 ). These variables were adjusted in the multivariate model. Table 5 shows that the presence of BMI and serum FBS, insulin, triglycerides, TSH andcombined groups 2 and 3 had a significant positive effect on T3:T4 ratio compared to group $\left(\mathrm{R}_{2}=0.26\right)$. 


\begin{tabular}{|c|c|c|c|}
\hline Variables & Group $1(N=130)$ & Group $2(N=73)$ & $\operatorname{Group} 3(N=52)$ \\
\hline Serum free T4, pmol/L & $15.4 \pm 3.7$ & $12.8 \pm 4.6^{\mathrm{c}}$ & $13.2 \pm 3.1^{\mathrm{d}}$ \\
\hline Serum T3, ng/dL & $120 \pm 37$ & $141 \pm 38^{\mathrm{c}}$ & $126 \pm 33$ \\
\hline T3:T4 ratio & $9.82 \pm 3.51$ & $14.62 \pm 5.17^{c}$ & $12.37 \pm 3.79^{\mathrm{d}, \mathrm{e}}$ \\
\hline Serum TSH, mU/L & $1.36(0.46-3.38)$ & $2.71(1.48-4.33)^{c}$ & $2.11(1.18-3.71)$ \\
\hline Serum TPOAb, IU/mL & $7(4-15)$ & $23(7-149)^{c}$ & $14(4-95)^{d}$ \\
\hline Serum TRAb, $\mathbf{U} / \mathbf{m L}$ & $1.76(1.25-2.15)$ & $2.0(1.6-3.85)^{c}$ & $1.2(0.55-1.85)^{\mathrm{d}, \mathrm{e}}$ \\
\hline \multicolumn{4}{|c|}{$\begin{array}{l}\text { Abbreviations: TPOAb, thyroid peroxidase antibody; TR } \\
\text { a'Group 1: Radioiodine-treated hypothyroid Graves' pat } \\
\text { patients off treatment for }>2 \text { years. } \\
\text { bValues are expressed as mean } \pm \text { SD and median (inter } \\
\text { ' } \text { Significant difference between group } 1 \text { and group } 2 \text {. } \\
{ }^{\mathrm{d}} \text { Significant difference between group } 1 \text { and group } 3 \text {. } \\
{ }^{\mathrm{e}} \text { Significant difference between group } 2 \text { and group } 3 \text {. }\end{array}$} \\
\hline Variables & Group $1(N=130)$ & Group $2(N=73)$ & Group $3(N=52)$ \\
\hline Male, No. \% & $21(15.0)$ & $18(24.7)$ & $8(14.8)$ \\
\hline Age, $y$ & $53.7 \pm 11.7$ & $50.7 \pm 16.14$ & $52.13 \pm 10.88$ \\
\hline WC, $\mathbf{c m}$ & $93.9 \pm 13.4$ & $90.2 \pm 10.8$ & $92.6 \pm 11.7$ \\
\hline BMI, $\mathrm{kg} / \mathrm{m}^{2}$ & $28.3 \pm 4.5$ & $26.6 \pm 4.3^{c}$ & $26.8 \pm 4.2$ \\
\hline Cholesterol, mg/dL & $203 \pm 33$ & $188 \pm 37^{c}$ & $195 \pm 31$ \\
\hline Triglycerides, mg/dL & $146(101-195)$ & $115(83-153)^{c}$ & $121(86-172)$ \\
\hline HDL-c, mg/dL & $49.4 \pm 12.3$ & $53.2 \pm 9.9$ & $53.0 \pm 13.5$ \\
\hline LDL-c, mg/dL & $111 \pm 23$ & $100 \pm 24^{c}$ & $108 \pm 24$ \\
\hline $\mathrm{FBS}, \mathrm{mg} / \mathrm{dL}$ & $99 \pm 19$ & $96 \pm 23$ & $96 \pm 16$ \\
\hline 2h PP BG, mg/dL & $121(92-150)$ & $105(83-136)$ & $122(101-144)$ \\
\hline Insulin, $\mathbf{m U} / \mathbf{L}$ & $6.40(3.51-9.05)$ & $5.60(3.70-9.13)$ & $4.91(2.89-8.73)$ \\
\hline HOMA-IR & $1.53(0.78-2.18)$ & $1.38(0.85-2.10)$ & $1.08(0.63-2.15)$ \\
\hline
\end{tabular}

Abbreviations: WC, waist circumference; BMI, body mass index; HDL-C, high-density lipoprotein-cholesterol; LDL-C, low-density lipoprotein-cholesterol; FBS, fasting blood sugar; HOMA-IR, homeostatic model assessment of insulin resistance.

${ }^{a}$ Group 1: Radioiodine-treated hypothyroid Graves' patients on LT4 treatment; group 2: Euthyroid Graves' patients on methimazole therapy; group 3: Euthyroid Graves' patients off treatment for $>2$ years.

${ }^{\mathrm{b}}$ Values are expressed as mean $\pm \mathrm{SD}$ and median (interquartile range), as appropriate.

${ }^{\mathrm{c}}$ Significant difference between group 1 and group 2 .

\section{Discussion}

The present study showed that compared to euthyroid Graves' patients, Graves' patients taking LT4 treatment following radioiodine treatment exhibited higher serum fT4, lower serum T3, and lower T3:T4 ratio, despite lower TSH levels. In addition, LT4-treated patients had higher BMI and deranged lipid profiles. Although previous studies demonstrated that not all systemic biological markers of thyroid hormone signaling normalized after LT4 monotherapy, this is the first report of the same phenomena in Graves' patients.

Previous studies have also shown the same results in the LT4 monotherapy settings, as compared to normal controls (2-4). The present study showed that serum concentrations of fT4, T3, and TSH, BMI, and lipid profiles in euthyroid Graves' subjects, like normal subjects, differed from those of patients taking LT4; this finding confirms previous suggestions that using exogenous LT4 fails to mimic all physiological effects exhibited by normal thyroid function $(3,14)$. It is well known that in euthyroid subjects, serum T3 and $\mathrm{T} 4$ levels are defined by thyroid secretion of both hormones, as well as T3 production from T4 in peripheral tissues via both type 1 and 2 deiodinase pathways. In contrast, in LT4-treated patients, the predominant source of circulating $\mathrm{T} 3$ is the production from $\mathrm{T} 4$ by type 2 deiodinase. 


\begin{tabular}{|c|c|c|c|}
\hline Variables & Total & Group 1 & Combined Groups 2 and 3 \\
\hline Age & 0.01 & $0.21^{\mathrm{c}}$ & -0.05 \\
\hline WC & -0.02 & -0.01 & 0.07 \\
\hline BMI & 0.06 & $0.20^{\mathrm{c}}$ & 0.11 \\
\hline Triglycerides $\dagger$ & 0.06 & $0.23^{\mathrm{c}}$ & 0.04 \\
\hline HDL-c & -0.03 & -0.14 & 0.07 \\
\hline LDL-c & -0.1 & 0.1 & -0.15 \\
\hline FBS & $-0.13^{c}$ & 0.02 & $-0.23^{c}$ \\
\hline Insulin $\dagger$ & $0.20^{\mathrm{c}}$ & $0.33^{\mathrm{c}}$ & 0.13 \\
\hline 2h PP BG, mg/dL & 0.02 & 0.13 & -0.09 \\
\hline HOMA-IR $\dagger$ & $0.15^{\mathrm{c}}$ & $0.31^{c}$ & 0.05 \\
\hline TPOAb $\dagger$ & $0.18^{\mathrm{c}}$ & -0.02 & 0.11 \\
\hline $\operatorname{TRAb} \dagger$ & 0.12 & 0.001 & $0.21^{\mathrm{c}}$ \\
\hline $\mathrm{TSH}_{\dagger}$ & $0.31^{c}$ & 0.17 & $0.38^{c}$ \\
\hline
\end{tabular}

${ }^{\mathrm{a}}$ For abbreviations, refer to footnotes of Tables 1 and 2 .

${ }^{\mathrm{b}}$ Pearson correlation coefficient was performed for all variables and Spearman test for those marked by $\dagger$.

${ }^{\mathrm{c}}$ Correlation is significant at the 0.05 level.

\begin{tabular}{lcc}
\hline Table 4. Univariate Regression & Analysis of & Variables and Serum T3:T4 Ratio \\
\hline Variables & Regression Coefficient & P Value \\
\hline Male gender & 0.53 & 0.448 \\
\hline Age & 0.02 & 0.359 \\
\hline WC & 0.01 & 0.67 \\
\hline BMI & 0.144 & 0.016 \\
\hline Cholesterol & -0.001 & 0.921 \\
\hline Triglycerides & 0.01 & 0.013 \\
\hline HDL-c & -0.04 & 0.112 \\
\hline LDL-c & -0.01 & 0.55 \\
\hline FBS & -0.03 & 0.064 \\
\hline Insulin & 0.07 & 0.089 \\
\hline HOMA-IR & 0.26 & 0.141 \\
\hline TPOAb & 0.001 & 0.632 \\
\hline TRAb & -0.001 & 0.992 \\
\hline TSH & 0.31 & $<0.001$ \\
\hline TH & & \\
\hline
\end{tabular}

${ }^{\mathrm{a}}$ For abbreviations, refer to footnotes of Tables 1 and 2.

Therefore, it is not surprising that, in this study, the T3:T4 ratio was $27 \%$ lower in LT4-treated individuals than in euthyroid Graves' patients.

Serum TPOAb was lower in group 1 than in the other two groups because of the ablation of thyroid cells by radioiodine treatment while thyroid cells were present in all
Table 5. Multivariate Regression Analysis of Associated Variables with the Serum T3:T4 Ratio

\begin{tabular}{lcc}
\hline & Regression Coefficient $(95 \%$ CI $)$ & P Value \\
\hline Combined groups 2 and 3 & $3.5(2.93,4.96)$ & $<0.001^{\mathrm{a}}$ \\
\hline TSH & $0.28(0.13,0.44)$ & $<0.001$ \\
\hline Triglycerides & $0.009(0.002,0.016)$ & 0.017 \\
FBS & $-0.04(-0.06,-0.01)$ & 0.009 \\
\hline BMI & $0.13(0.01,0.24)$ & 0.048 \\
Insulin & $0.06(-0.04,-0.13)$ & 0.283 \\
\hline
\end{tabular}

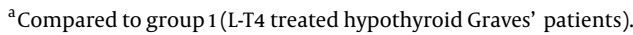

group 2 and some group 3 patients. Serum TRAb was lower in group 3 than in other two groups; this was due to remission status of hyperthyroidism in the majority of patients in group 3. In addition, patients in group 2 that had been treated with MMI for approximately two years had higher TRAb values than those in groups 1 and 3 and the stimulation of TSH receptor and driving of $\mathrm{D}_{3}$ may have been responsible for further increase in the T3: $\mathrm{T} 4$ ratio. This may also explain the higher $\mathrm{T} 3$ : $\mathrm{T} 4 \mathrm{ratio}$ in group 2 than in group 3 patients.

The ability of the human body to generate T3 in patients with hypothyroidism treated with LT4 has been known since classic studies demonstrating normal serum T3 values in LT4 monotherapy in hypothyroid patients (7, 15); however, the results of such early studies have lim- 
ited direct application to the present LT4 therapy because the doses of LT4 were much higher than currently administered doses. It was also demonstrated that when fT4 or T4 index values were elevated, the serum T3:T4 ratios were lower than euthyroid controls, suggesting a protective downregulation of type 2 deiodinase (16).

In the new era of lower LT4 doses with the employment of sensitive TSH measurements to avoid thyrotoxic doses of LT4, studies have shown that in adequately treated hypothyroid patients with LT4, serum total T4 and FT4 are higher than control values; therefore, T3:T4 ratios are lower than control values $(17,18)$.

The relationship between decreased T3:T4 ratio in LT4treated patients and demographic and biochemical variables is not fully understood. In order to respond to the question whether using LT4 alone in hypothyroid status could ensure thyroid hormone actions simultaneously in all tissues, an animal study conducted 24 years ago found that in thyroidectomized rats, treatment with $\mathrm{T} 4$ per se was unable to provide both normal T4 and T3 concentrations simultaneously in plasma and all tissues. In addition, they could not ensure normal T3 levels in all tissues of rats, even at the expense of excessive T4 concentrations (10). Moreover, studies have shown that the physiology of thyroid hormone secretion and metabolism in rats is quite different from what occurs in humans $(19,20)$.

Saravanan et al. in a community-based study, demonstrated that in LT4-treated hypothyroid subjects, even those with normal serum TSH, showed significant deficits in psychological well-being tests, compared to normal controls. The authors suggested that significant psychological morbidity occurred in a substantial number of LT4-treated individuals; however, in their 2006 report, they found no correlation of health-related quality of life-12 (GHQ-12) and the thyroid symptom questionnaire with serum $\mathrm{T} 3$ concentration (21). In the current decade, three additional studies have shed more light on this subject. Gullo et al. in 2011 stated that LT4 monotherapy cannot guarantee euthyroidism in athyreotic patients because these individuals have a highly heterogeneous T3 production capacity from orally administered LT4, resulting in abnormal T3:T4 ratios in over $20 \%$ of them (2). Samuels et al. found normal energy expenditure (REE) and body composition in LT4-suppressed subjects but decreased REE in LT4 euthyroid women, accompanied by lower mean fT3 levels (4). Finally, Peterson et al. showed that based on NHANES data, those using LT4 had lower serum fT3:fT4 ratio and differed in 12/52 metabolic variables from healthy controls; however, only a few clinical parameters were significantly related to the free fT3:fT4 ratio and the strength of the association was not always impressive (3); they reported that age, female sex, and serum creatinine were negatively and BMI, total cholesterol, and triglycerides were positively associated with serum fT3:fT4 ratio.

We previously found that LT4-treated patients have increased BMI (21) and deranged lipid profiles (22), when compared to euthyroid Graves' subjects on long-term MMI treatment. It is noteworthy to mention that many factors may influence weight differences between groups, including the periods of transient hypo- or hyperthyroidism, treatment of hyperthyroidism, gastrointestinal upset due to drugs, and lifestyle changes of participant; therefore, the difference in BMI between groups should be considered with caution. A meta-analysis of 99 studies with LT4 monotherapy showed increases in serum LDL-C and triglycerides concentrations in LT4-treated participants (14).

What does the T3:T4 ratio mean in LT4-treated individuals and what is its contribution to differences in some variables between these individuals and the normal population? Although it has been suggested that fT3:fT4 ratio is more associated with metabolic parameters than TSH in normal subjects (23), the clinical implication of the present study findings is not clear in this respect. Regression coefficients found in multivariate regression analysis of associated variables with the serum T3:T4 ratio (Table 5) showed that actual variance explained by this model was minimal and may be devoid of clinical significance.

The main strength of the present study is that it is the first study that compares some thyroid-related variables between Graves' patients on LT4 treatment and euthyroid Graves' patients; the differences were similar to those reported between LT4-treated and normal subjects (3). A major limitation of this study is that patients on MMI therapy may not be a valid comparison group for the LT4-treated group; however, some of the results could also be seen in the subgroup of Graves' patients off MMI therapy for $>2$ years. In addition, having a control group might have better defined the differences observed. There are also other limitations, as follows. The cross-sectional study cannot ascertain causality. We were not sure if the groups differed prior to treatment. Not all parameters related to the effect of thyroid hormones were examined. Many confounders were not studied and sources of recall bias may exist. Lastly, we did not have access to full baseline data of the three groups, in particular, body weight and BMI and their precise increment throughout the length of clinical changes in patients of both groups.

In conclusion, the present study showed that LT4treated Graves' subjects had more general obesity, higher fT4, serum cholesterol, LDL-C, and triglycerides and lower serum HDL-C, serum TSH, T3, and T3:T4 ratio, when compared to euthyroid Graves' subjects. This observation may suggest that LT4 monotherapy may not be the ideal treat- 
ment for Graves' hypothyroid patients.

\section{Footnotes}

Authors' Contribution: Fereidoun Azizi designed the study; Fereidoun Azizi and Atieh Amouzegar contributed to interpretation of data and drafted the manuscript; Maryam Tohidi and Mehdi Hedayati contributed to laboratory analyses and participated in the acquisition of data; Leila Cheraghi and Yadollah Mehrabi carried out the statistical analysis and contributed to interpretation of data. All authors read and approved the final manuscript.

Conflict of Interests: The authors have no conflict of interests to declare.

Ethical Approval: The protocol of the study was approved by the Ethics Committee of the Research Institute for Endocrine Sciences.

Funding/Support: There is no funding/support.

Patient Consent: Subjects gave written informed consent prior to enrollment.

\section{References}

1. Smith TJ, Hegedus L. Graves' disease. NEnglJ Med. 2016;375(16):1552-65. doi: 10.1056/NEJMra1510030. [PubMed: 27797318].

2. Gullo D, Latina A, Frasca F, Le Moli R, Pellegriti G, Vigneri R. Levothyroxine monotherapy cannot guarantee euthyroidism in all athyreotic patients. PLoS One. 2011;6(8). e22552. doi: 10.1371/journal.pone.0022552. [PubMed: 21829633]. [PubMed Central: PMC3148220].

3. Peterson SJ, McAninch EA, Bianco AC. Is a Normal TSH synonymous with "euthyroidism" in levothyroxine monotherapy? J Clin Endocrinol Metab. 2016;101(12):4964-73. doi: 10.1210/jc.2016-2660. [PubMed: 27700539]. [PubMed Central: PMC6287526].

4. Samuels MH, Kolobova I, Smeraglio A, Peters D, Purnell JQ, Schuff KG. Effects of levothyroxine replacement or suppressive therapy on energy expenditure and body composition. Thyroid. 2016;26(3):347-55. doi: 10.1089/thy.2015.0345. [PubMed: 26700485]. [PubMed Central: PMC4790206].

5. Saravanan P, Chau WF, Roberts N, Vedhara K, Greenwood R, Dayan CM. Psychological well-being in patients on 'adequate' doses of 1-thyroxine: Results of a large, controlled community-based questionnaire study. Clin Endocrinol (Oxf). 2002;57(5):577-85. doi: 10.1046/j.1365-2265.2002.01654.x. [PubMed: 12390330].

6. Jonklaas J, Bianco AC, Bauer AJ, Burman KD, Cappola AR, Celi FS, et al. Guidelines for the treatment of hypothyroidism: Prepared by the american thyroid association task force on thyroid hormone replacement. Thyroid. 2014;24(12):1670-751. doi: 10.1089/thy.2014.0028. [PubMed: 25266247]. [PubMed Central: PMC4267409].

7. Braverman LE, Ingbar SH, Sterling K. Conversion of thyroxine (T4) to triiodothyronine (T3) in athyreotic human subjects. J Clin Invest. 1970;49(5):855-64. doi: 10.1172/JCl106304. [PubMed: 4986007]. [PubMed Central: PMC535757].

8. McAninch EA, Bianco AC. The history and future of treatment of hypothyroidism. Ann Intern Med. 2016;164(1):50-6. doi: 10.7326/M15-1799. [PubMed: 26747302]. [PubMed Central: PMC4980994].

9. Wiersinga WM, Duntas L, Fadeyev V, Nygaard B, Vanderpump MP. 2012 ETA guidelines: The use of L-T4 + L-T3 in the treatment of hypothyroidism. Eur Thyroid J. 2012;1(2):55-71. doi: 10.1159/000339444. [PubMed: 24782999]. [PubMed Central: PMC3821467].
10. Escobar-Morreale HF, Obregon MJ, Escobar del Rey F, Morreale de Escobar G. Replacement therapy for hypothyroidism with thyroxine alone does not ensure euthyroidism in all tissues, as studied in thyroidectomized rats. J Clin Invest. 1995;96(6):2828-38. doi: 10.1172/JCl118353. [PubMed: 8675653]. [PubMed Central: PMC185993].

11. Allannic H, Fauchet R, Orgiazzi J, Madec AM, Genetet B, Lorcy Y, et al. Antithyroid drugs and Graves' disease: A prospective randomized evaluation of the efficacy of treatment duration. J Clin Endocrinol Metab. 1990;70(3):675-9. doi: 10.1210/jcem-70-3-675. [PubMed: 1689737].

12. Franklyn JA, Daykin J, Drolc Z, Farmer M, Sheppard MC. Longterm follow-up of treatment of thyrotoxicosis by three different methods. Clin Endocrinol (Oxf). 1991;34(1):71-6. doi: 10.1111/j.13652265.1991.tb01738.x. [PubMed: 2004475].

13. Azizi F, Ghanbarian A, Momenan AA, Hadaegh F, Mirmiran P, Hedayati $\mathrm{M}$, et al. Prevention of non-communicable disease in a population in nutrition transition: Tehran Lipid and Glucose Study phase II. Trials. 2009;10:5. doi: 10.1186/1745-6215-10-5. [PubMed: 19166627]. [PubMed Central: PMC2656492].

14. McAninch EA, Rajan KB, Miller CH, Bianco AC. Systemic thyroid hormone status during levothyroxine therapy in hypothyroidism: A systematic review and meta-analysis. J Clin Endocrinol Metab. 2018. doi: 10.1210/jc.2018-01361. [PubMed: 30124904]. [PubMed Central: PMC6226605].

15. Surks MI, Schadlow AR, Oppenheimer JH. A new radioimmunoassay for plasma L-triiodothyronine: Measurements in thyroid disease and in patients maintained on hormonal replacement. J Clin Invest. 1972;51(12):3104-13. doi: 10.1172/JC1107137. [PubMed: 4539287]. [PubMed Central: PMC332992].

16. Salmon D, Rendell M, Williams J, Smith C, Ross DA, Waud JM, et al. Chemical hyperthyroidism: Serum triiodothyronine levels in clinically euthyroid individuals treated with levothyroxine. Arch Intern Med. 1982;142(3):571-3. doi: 10.1001/archinte.142.3.571. [PubMed: 7065792].

17. Hennessey JV, Evaul JE, Tseng YC, Burman KD, Wartofsky L. L-thyroxine dosage: A reevaluation of therapy with contemporary preparations. Ann Intern Med. 1986;105(1):11-5. doi: 10.7326/0003-4819-105-1-11. [PubMed: 3087253 ].

18. Fish LH, Schwartz HL, Cavanaugh J, Steffes MW, Bantle JP, Oppenheimer JH. Replacement dose, metabolism, and bioavailability of levothyroxine in the treatment of hypothyroidism. Role of triiodothyronine in pituitary feedback in humans. $N$ Engl $J$ Med. 1987;316(13):764-70. doi: 10.1056/NEJM198703263161302. [PubMed: 3821822].

19. DiStefano J3, Jang M, Malone TK, Broutman M. Comprehensive kinetics of triiodothyronine production, distribution, and metabolism in blood and tissue pools of the rat using optimized blood-sampling protocols. Endocrinology. 1982;110(1):198-213. doi: 10.1210/endo-110-1198. [PubMed: 7053984]

20. Chanoine JP, Braverman LE, Farwell AP, Safran M, Alex S, Dubord S, et al. The thyroid gland is a major source of circulating T3 in the rat.J Clin Invest. 1993;91(6):2709-13. doi: 10.1172/JC1116510. [PubMed: 8514878]. [PubMed Central: PMC443335].

21. Saravanan P, Visser TJ, Dayan CM. Psychological well-being correlates with free thyroxine but not free 3,5,3'-triiodothyronine levels in patients on thyroid hormone replacement. J Clin Endocrinol Metab. 2006;91(9):3389-93. doi: 10.1210/jc.2006-0414. [PubMed: 16804044].

22. Azizi F, Yousefi V, Bahrainian A, Sheikholeslami F, Tohidi M, Mehrabi Y. Long-term continuous methimazole or radioiodine treatment for hyperthyroidism. Arch Iran Med. 2012;15(8):477-84. [PubMed: 22827783].

23. Park SY, Park SE, Jung SW, Jin HS, Park IB, Ahn SV, et al. Free triiodothyronine/free thyroxine ratio rather than thyrotropin is more associated with metabolic parameters in healthy euthyroid adult subjects. Clin Endocrinol (Oxf). 2017;87(1):87-96. doi: 10.111//cen.13345. [PubMed: 28374508]. 